\title{
Assessing the capability of terrestrial laser scanning for monitoring slow moving landslides
}

\author{
A. Prokop and H. Panholzer \\ Institute of Mountain Risk Engineering, Department of Civil Engineering and Natural Hazards, University of Natural \\ Resources and Applied Life Sciences, Peter Jordanstrasse 82, 1190 Wien, Austria
}

Received: 1 December 2008 - Revised: 6 August 2009 - Accepted: 15 October 2009 - Published: 19 November 2009

\begin{abstract}
Digital elevation models (DEM) are widely used to determine characteristics of mass movement processes such as accumulation and deposition of material, volume estimates or the orientation of discontinuities. To create such DEMs point cloud data is provided by terrestrial laser scanning (TLS) and recently used for analysis of mass movements. Therefore the reliability of TLS data was investigated in a comparative study with tachymetry. The main focus was on the possibility of determining movement patterns of landslides $<100 \mathrm{~mm}$. Therefore, several post processing steps are needed and the reliability of those were analyzed. The post processing steps that were investigated include: (1) The registration process is a crucial step considering long term TLS monitoring of an object and can be significantly improved using an iterative closest point (ICP) algorithm; (2) Filtering methods are necessary to create DEMs in order to separate favored laser points on the terrain surface (ground points) from topographically irrelevant points (non-ground-points). Therefore GIS tools were applied. Surfaces with and without vegetation cover were differentiated; (3) Displacement vectors are used to determine slope movement rates. They were created from TLS data after the computation of true orthophotos.

Using the methodology presented it was not possible to determine movement rates $<50 \mathrm{~mm}$ per period. However, if the quality of the point density is described and areas with very low point density are detected, reliable conclusions can be made regarding slope movement patterns and erosion and deposition of material for changes $<100 \mathrm{~mm}$ for the investigated slope.
\end{abstract}

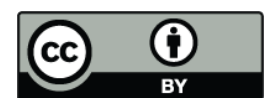

Correspondence to: A. Prokop (alexander.prokop@boku.ac.at)

\section{Introduction}

Landslides are a major natural hazard threatening the inhabitants of many mountainous regions. Population increase and extension of inhabited areas into potentially hazardous locations leads to a significant increase of potential losses in the case of a disaster (Oppikofer et al., 2008). Therefore, landslides have been investigated in various ways.

Terrestrial laser scanning (TLS) is used as an observation method in hazard assessment (e.g. Biasion et al., 2005; Prokop, 2008). Thereby, 3-D data from changing landscape surfaces is collected at different states to monitor hazardous processes. The point cloud data can be analyzed in various ways such as a point to point comparison (Oppikofer et al., 2008) or comparison after the creation of digital elevation models (DEM) (Abellan et al., 2006). To monitor mass movements differences in structural characteristics can be investigated, such as accumulation and deposition behaviour of material (Prokop and Panholzer, 2007), volume estimates or the orientation of discontinuities (Derron, et al., 2005).

Various data sources have been used in the past to create such DEMs, including photogrammetry (Dewitte and Demoulin, 2005; Voyat, et al., 2006) or radar interferometry (Pieraccini et al., 2003). While laser scanning provides 3$\mathrm{D}$ information with greater density than alternative methods (Bitelli et al., 2004; Prokop and Panholzer, 2007), data obtained using a terrestrial laser scanner is represented as unstructured and scattered accumulations of points. Therefore, intensive post-processing of the data is required. Various approaches of filtering data obtained from airborne laser scanning exist: auto-regressive process (Lindenberger, 1993), mathematical morphology (Kilian et al., 1996), method of smallest squares robust interpolation (Pfeifer et al., 1998), convex-concave hull (Von Hansen et al., 1999), procedures based on a triangulation of the DEM using local terrain slope

Published by Copernicus Publications on behalf of the European Geosciences Union. 
as a filtering criterion (Axelsson, 2000; Vosselmann, 2000; Vosselmann and Maas, 2001), gridding procedures determining a grid-DEM in a data pyramid by hierarchically including elevation values based on gradients (Wack and Wimmer, 2002; Sithole and Vosselmann, 2003). However, data filtering always means a loss of data and sometimes of information. The quality of the DEM created depends on the method applied and the structure of the landscape (Hamrah et al., 2006).

The relevance of such DEMs concerning the analysis of mass movement processes was investigated for airborne laser data (Schulz, 2007; Scheidl et al., 2008). For the terrestrial approach an investigation of automated filtering methods concerning the accuracy of DEMs created and the interpretation of mass movement processes has yet to be completed, although TLS data has been used for monitoring mass movements, e.g. for rock falls (Biasion, et al., 2005; Mikos, et al., 2005; Voyat, et al., 2006; Oppikofer, et al., 2008) and for landslide masses (Hsiao, et al., 2003; Bitelli, et al., 2004). The cited cases of mass movements involved large amounts of material moved by the process (movement rates $>10 \mathrm{~cm}$ per investigated period). A thorough investigation of the laser data accuracy was therefore not necessary (most terrestrial laser scanners available on the market today measure ranges to objects of up to several hundred meters, with a single point accuracy of $1.4-15 \mathrm{~mm}$ at $50 \mathrm{~m}$; Ingensand, 2006).

To be able to analyse the reliability, including post processing steps, of TLS data, it is necessary to perform the measurement with the greatest possible accuracy. The accuracy of TLS measurements in mountainous environments depends on several factors (Prokop, 2008b). According to those factors it was necessary for the test site to meet (and it did meet) the following conditions:

1. The distance between the scanner position and the slope monitored is within a range of $\sim 100 \mathrm{~m}$ (expected accuracy of the measurement is within a range of $3 \mathrm{~cm}$ )

2. The expected movement rate within the test period is $5-15 \mathrm{~cm}$

3. The test area is easy reachable by car, a power supply is available and the laser device is protected against external forces such as wind and solar radiation

4. The monitored slope is $70 \%$ free of vegetation

5. The incident angle of the laser beam on the slope is $<60^{\circ}$ (an incident angle of $0^{\circ}$ indicates the laser beam is perpendicular to the ground; so that the footprint is a circle)

6. Comparison of TLS with tachymetry can be executed

An investigation of the accuracy of TLS data and applied post processing steps for DEM creation is needed for slow moving landslides (movement rates $<10 \mathrm{~cm}$ per investigated period). Accuracy limitations in the creation of DEMs and interpretation of TLS data concerning movement patterns of landslides are discussed and case examples are presented. The results are evaluated against tachymetry measurements (a reliable alternative surveying method) and a comparative study is given. A point to point comparison of TLS data for mass movement analyses has already been investigated by Oppikofer et al. (2008) and is therefore not the subject of this paper.

\section{The "Galierm" landslide}

The test site, "Galierm" landslide (Fig. 1), is located northeast of the town of Schruns in the area of Montafon (Vorarlberg, Austria) above the bank of Litz stream (Fig. 1a). The Montafon valley is located on the border between the northern limestone alps and the main core of the upper eastern alps, which arises in the crystalline bedrock of the Silvretta mountain ridge. In the area of the "Galierm" landslide there are gneisses including layers of white quarz.

A high water event at the Litz stream in 2005 (Fig. 1c: dashed light blue line) caused significant erosion of the bank. A weak section of the stream bank initiated significant movement of the whole slope above. The dimensions of the moving slope section are approximately $100 \times 100 \mathrm{~m}$ (Fig. 1c: dashed yellow line).

\section{Data acquisition}

To monitor the movement patterns of the slope, the Riegl LMS z420i TLS device was used (http://www.riegl.com). For technical features of the device used see Table 1. Between March 2006 and September 2007 six data acquisitions in a time interval of approximately 5 months using both measurement methods, terrestrial laser scanning and tachymetry, were executed to monitor the moving slope, "Galierm". An additional survey was conducted one day after the first acquisition of data to test the reproducibility of the measurements (reproducibility is defined as the closeness of two measurements regarding the same object carried out under different measurement conditions). The data acquisition steps included:

1. Location of a stable scanner position allowing reasonable angles of incidence on the target surface

2. Installation of a rigid geodetic network (red points in Fig. 1c) allowing registration of both laser scanner position and tachymetry (registration is likely the most crucial step in long term TLS monitoring of an object, Prokop et al., 2008). 


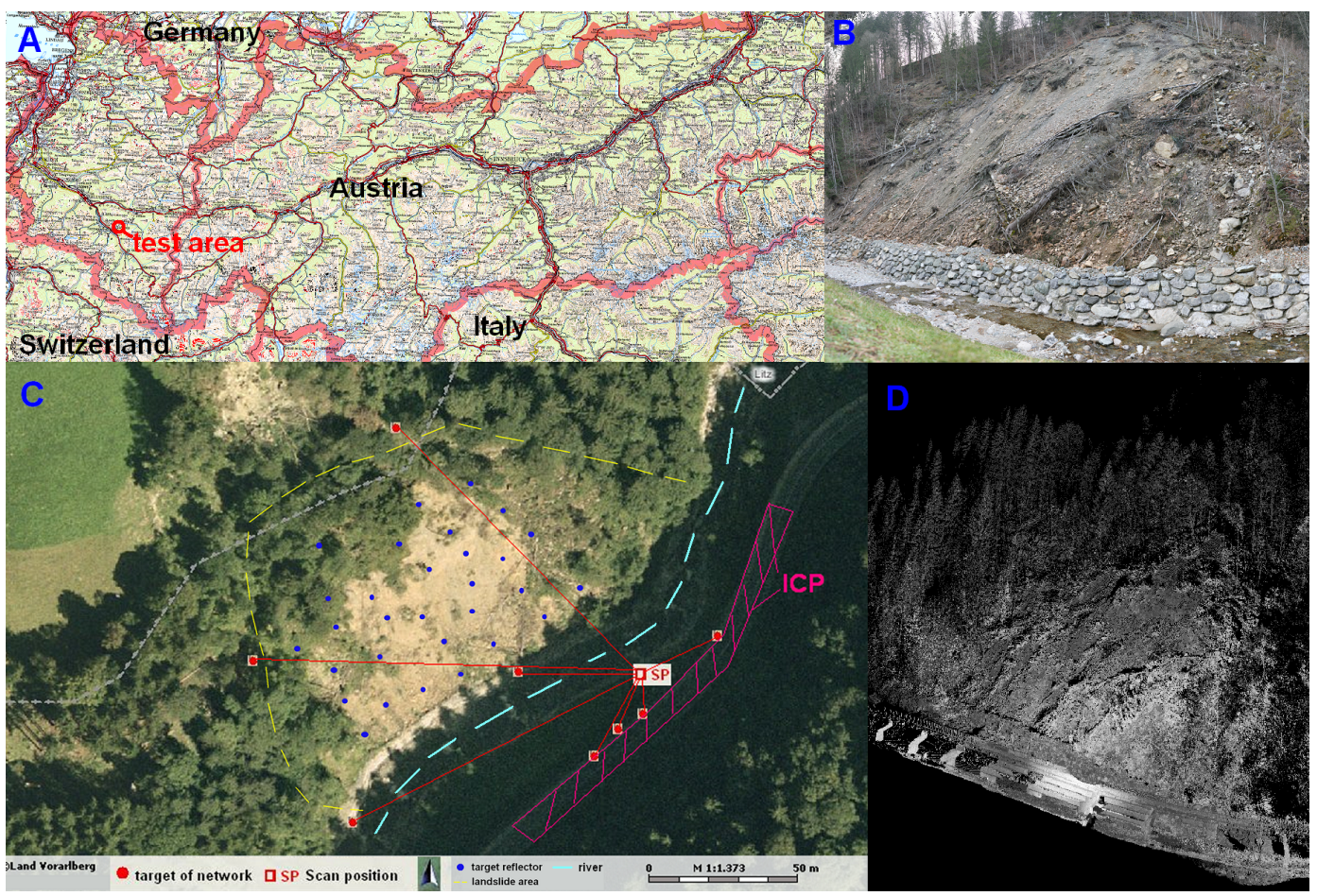

Fig. 1. The test site Galierm. (A) Location of the test site (cut of the Austrian Map 1:500 000 distorted). (B) Picture of the test site. (C) Map of test site location. (D) Point cloud of the test area.

3. Laser scanning process including image acquisition that is collected by cameras mounted on the scanning device to create orthophotos.

The whole test area was scanned by TLS using a point resolution of $3 \mathrm{~cm}$ at a distance of $100 \mathrm{~m}$. The chosen resolution was slightly lower than the ideal point spacing of $86 \%$ of the beam width according to Lichti and Jamtsho (2006) due to the large amount of points per scan (approximately 5000000 points). Handling of point clouds consisting of a greater number of points is difficult when using GIS- tools.

To compare TLS with tachymetry, data targets (blue dots in Fig. 1c) were positioned within the test area and were measured by both methods. Furthermore, significant structures such as discernable rocks within the test area were selected, located and point measurements were executed by tachymetry using reflectors. For comparison, the position of the selected significant structures was identified within the laser data in a post processing step using orthophotos that were created.

\section{Post processing}

The data point cloud is heterogeneously distributed depending on the characteristics of the laser scanned target (e.g. different distances and angles of incidences). Furthermore vegetation and objects within the scanned area create points that
Table 1. Technical features of the used long rang laser measuring system (Riegl, 2005).

\begin{tabular}{ll}
\hline Riegl LMS Z420i & \\
\hline Range/good reflecting targets & $1000 \mathrm{~m}$ \\
Range/bad reflecting targets & $350 \mathrm{~m}$ \\
Wavelength & $1.5 \mu \mathrm{m}$ \\
Measurement accuracy & $10 \mathrm{~mm}$ \\
Beam divergence & $0.25 \mathrm{mrad}$ \\
Resolution (highest resolution in a range of $10 \mathrm{~m})$ & $1 \mathrm{~mm}$ \\
Measurement rate & 8000 Points $/ \mathrm{s}$ \\
Temperature range & $0^{\circ} \mathrm{C}$ to $+50^{\circ} \mathrm{C}$ \\
\hline
\end{tabular}

do not belong to the ground surface of the investigated slope. After the creation of DEMs, post processing methods need to be established, which included the following steps for the Galierm landslide:

1. Registration using tie point targets (reflectors) of the geodetic network (red points in Fig. 1c)

2. Registration using iterative closest point (ICP) algorithm. The ICP algorithm is an iterative alignment algorithm that works in three phases: (1) establish correspondence between pairs of features in the two structures that are to be aligned based on proximity, (2) estimate the rigid transformation that best maps the first 

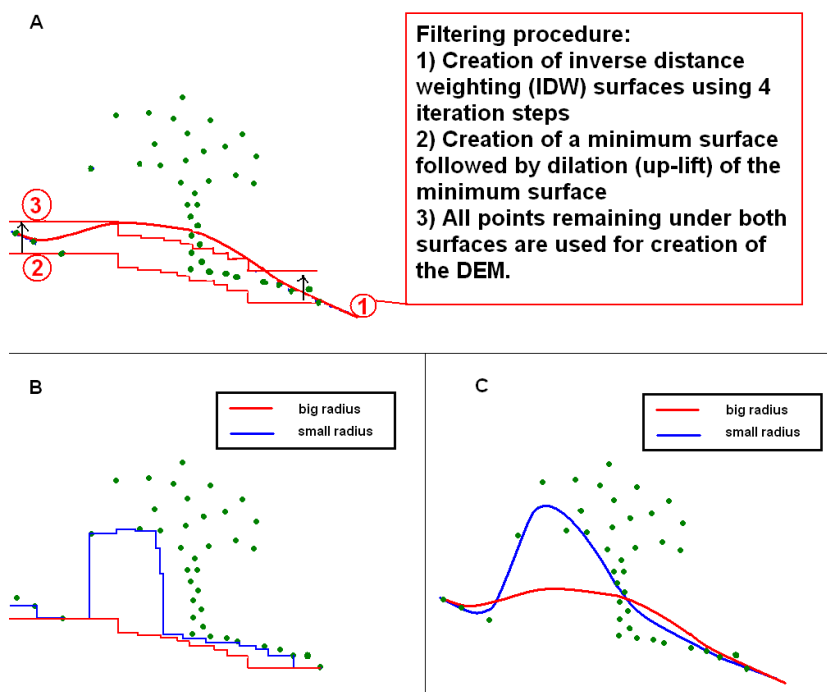

Fig. 2. (A) Filtering procedure. (B and C) Influences of point density on surface creation. (B) Minimum surface creation depending on the chosen radius for surface calculations. (C) Inverse distance weighting surface creation depending on the chosen radius for surface calculations.

member of the pair onto the second and then (3) apply that transformation to all features in the first structure. These three steps are then reapplied until convergence is concluded (Besl and McKay, 1992). The ICP algorithm tool used was provided by the laser scanner software RiScan Pro called "Multi station adjustment" (http://www.riegl.com). The algorithm works best with the use of plane surfaces. A number of 30 plane surfaces were available due to the presence of a concrete road close to the test area, which was very stable in contrast to the moving slope.

3. Data quality check: Reproducibility tests of fixed objects within the scan area were executed (reproducibility is defined as closeness of the results of two measurements taken from the same object carried out under different measurement conditions. In this case, the different conditions included variations in scanner set-up, atmospheric conditions, time of day and discrete registration). In case of scan misalignment with respect to each other, scans are sorted out allowing a maximum deviation of $2 \mathrm{~cm}$.

4. Data filtering: Separation of laser points on the terrain surface (ground points) from the topographically irrelevant points (non-ground-points): Two methods were applied: (1) Operator based: Knowing the test area very precisely, the operator manually deletes irrelevant points using the software RiScan Pro. This method is very time-consuming. (2) Automated: GIS (ArcGIS 9.2) tools were used to filter the data. The following procedure was applied and can be seen in Fig. 2a: (a) Creation of inverse distance weighting (IDW) surfaces using 4 iteration steps, (b) Creation of a minimum surface followed by dilation (up-lift) of the minimum surface, (c) All points remaining under both surfaces are used for creation of the DEM. When creating the IDW and minimum surfaces the operator needs to defined a radius on the $\mathrm{x}$,y plane as a basis for calculation to filter points on the height-axis. Differences in surface creation depending on the defined radius and the method applied can be seen in Fig. 2b and c. An example of a detail of the point cloud (tree including its measurement shadow) is shown for the two cases.

5. Interpolation and creation of DEMs: After using different types of geo-statistical methods involving GIS (ArcGIS 9.2) such as Kriging, Radial Basis Function, TOPOGRID and Natural Neighbour; Natural Neighbour was considered to be the optimal method concerning the existing sources (see also Hamrah et al., 2006). The DEMs created were used for analyses.

6. Creation of orthophotos: Colour information from digital pictures was used to texture the surfaces of the DEMs within RiScan Pro. It is necessary to create orthophotos to locate the positions of the same points on different surface hulls. Those orthophotos are computed within the scanner software by triangulating the filtered point cloud with a surface, which is further textured by colour information from digital pictures. Those textured DEMs were used to identify significant structures within the test area for analyzing slope movements by creating displacement vectors.

\section{Analyses and calculation of slope movement patterns}

Analyses concerning the accuracy of TLS in comparison to tachymetry data were executed for 6 datasets monitoring the moving slope in the following manners (one dataset was sorted out due to missing quality, determined by the data quality check):

1. The two different registration methods (tie points and ICP algorithm) were compared (3-D accuracy of the measured points)

2. 30 reflecting targets within the test area were measured by both TLS and tachymetry. Their coordinates were compared and the deviation was computed (point to point comparison).

3. 30 significant points on structures were measured by tachymetry and were compared to DEMs created from TLS data. The shortest deviation between the tachymetry point coordinates and the created surface (DEM) was computed (point to surface comparison). 
Furthermore data was distinguished between surfaces with or without vegetation cover and manually or automatically filtered TLS data.

4. As for analysis of slope movements, displacement vectors are of great interest, the sizes and directions (trend and plunge) of vectors can be compared. After locating the same points (e.g. stones and rocks) the change of their position between two monitoring activities is described by displacement vectors. If the direction of the vectors were constant the sizes of those vectors were then compared to the tachymetry measurement to validate the quality of laser data. The determination of direction deviations was excluded from this work, since the displacement direction of the landslide was obviously not known in advance. For analysing landslide movement patterns knowing the directions of movements is a crucial factor. Ensuing future work will focus on accuracy determination of variable displacement directions as mentioned by Abellan et al. (2009).

5. After DEM creation, erosion and deposition zones were detected by calculating differences in height (h-axis) or volume between two DEMs.

\section{Results and discussion}

Results of the accuracy of TLS measurements including post processing steps in comparison to tachymetry are shown in Table 2. The tachymetry measurement acts as the reference system (error of the tachymetry measurements is $<15 \mathrm{~mm}$, as determined by reproducibility tests) and deviations of the TLS measurement are recorded.

The first step was to analyse the registration process. The quality of the registration process could be improved by using an ICP algorithm leading to a reduction of the standard deviation could be reduced from $8 \mathrm{~mm}$ to $4 \mathrm{~mm}$. It is important to mention that it was only possible to do that by using planar surfaces for running the ICP algorithm, such surfaces were provided by the geometry of a concrete road (Fig. 1). When using natural ground surfaces, such as rocks or trees, the ICP algorithm did not substantially reduce the registration error due to difficulties in defining planar surfaces from the given point cloud geometries.

Furthermore, the coordinates of reflecting targets that were measured by both TLS and tachymetry were compared. As expected, deviation between the two methods is limited (mean: $9 \mathrm{~mm}$, max: $17 \mathrm{~mm}$ ). The error is explained by the less accurate TLS measurement and inaccurately finding the exact centre of the target within the scanner software. However, the advantage of TLS, especially in comparison to tachymetry, is the spatial information over the whole land slide area, rather than precise point information as provided by tachymetry.

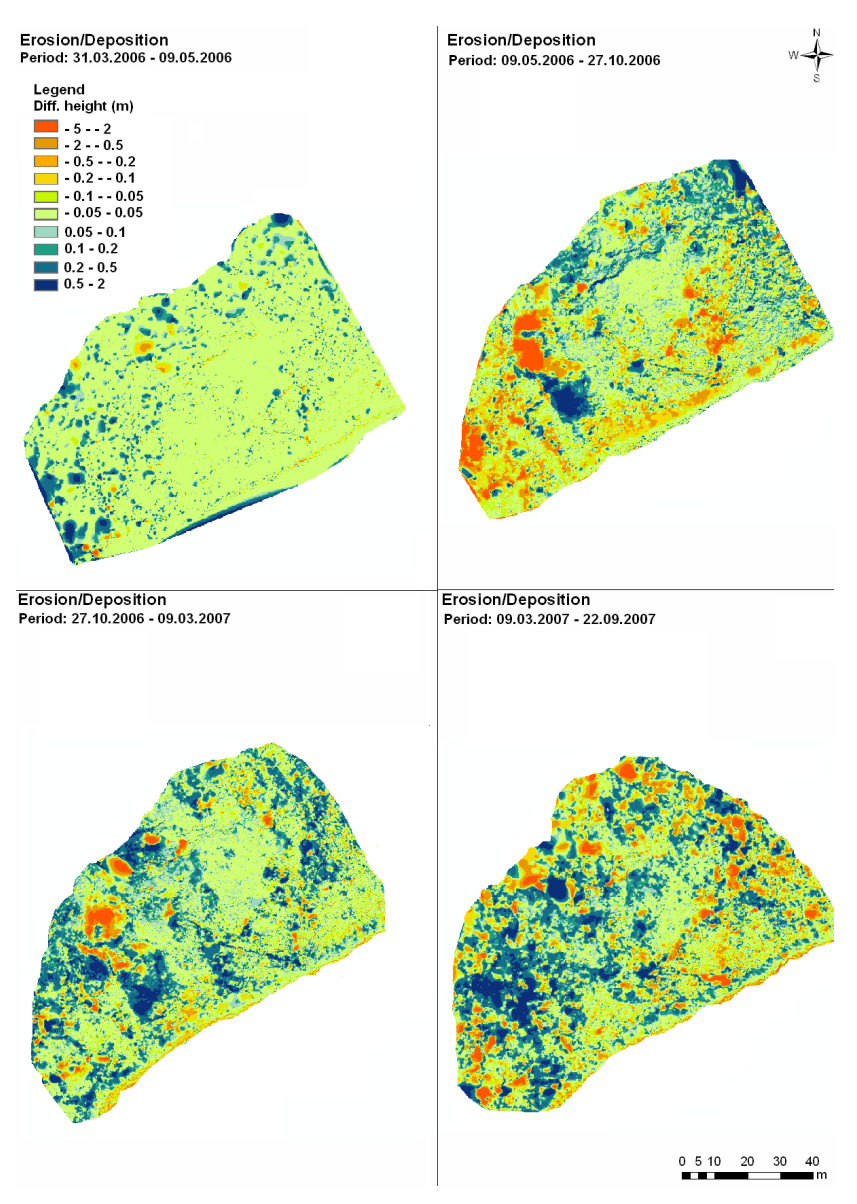

Fig. 3. Erosion and deposition of material for the investigated slope shown by differential maps.

The deviations of the DEM created from TLS data with the tachymetry point measurements are computed. Four different cases of DEM creations are shown. The first two deal with surfaces without vegetation cover. In one case manual and in the other case automated filtering of the scan data is applied. The manually filtered DEM shows slightly smaller deviations (mean: $23 \mathrm{~mm}$, max: $51 \mathrm{~mm}$ ) than the automatically filtered DEM (mean: $37 \mathrm{~mm}$, max: $63 \mathrm{~mm}$ ). The deviations are explained by the interpolation process of the filtered but unstructured point cloud rather than by the filter process itself, since almost only ground points exist on such surfaces. However, a certain smoothing effect of the automatically filtered DEM surface is likely to produce the larger deviations.

In final two cases surfaces with vegetation cover were filtered by the two respective methods. The deviations from tachymetry measurements increased significantly. While manually filtered surfaces delivered reasonable deviations (mean: $51 \mathrm{~mm}$, max: $88 \mathrm{~mm}$ ), the automatic filter applied did not satisfy an accuracy limitation of $<100 \mathrm{~mm}$ (mean: $127 \mathrm{~mm}$, max: $1875 \mathrm{~mm}$ ). The reason for this outcome is the reduced point density and more unstructured distribution of the point cloud in vegetation zones. The automatic filter (for 
Table 2. Deviations between TLS and tachymetry data.

\begin{tabular}{|c|c|c|c|c|}
\hline & sample size per scan & sample size overall & mean deviation $(\mathrm{mm})$ & maximum deviation $(\mathrm{mm})$ \\
\hline Registration TLS & 8 & 40 & & \\
\hline tie points & points & points & 8 & 16 \\
\hline Registration TLS & 10 & 50 & & \\
\hline ICP-algorithm & planes & planes & 4 & 14 \\
\hline Reflector coordinates & 30 & 150 & & \\
\hline TLS/tachymetry & points & points & 9 & 17 \\
\hline Tachymetry point to TLS surface & 20 & 100 & & \\
\hline manual filter/no vegetation & points & points & 23 & 51 \\
\hline Tachymetry point to TLS surface & 10 & 50 & & \\
\hline autom. filter/no vegetation & points & points & 37 & 63 \\
\hline Tachymetry point to TLS surface & 20 & 100 & & \\
\hline manual filter/vegetation & points & points & 51 & 88 \\
\hline Tachymetry point to TLS surface & 10 & 50 & & \\
\hline autom. filter/vegetation & points & points & 127 & 1875 \\
\hline displacement vectors & 20 & 80 & & \\
\hline no vegetation & 3-D-vectors & 3-D-vectors & 41 & 81 \\
\hline displacement vectors & 10 & 40 & & \\
\hline vegetation & 3-D-vectors & 3-D-vectors & 56 & 78 \\
\hline
\end{tabular}

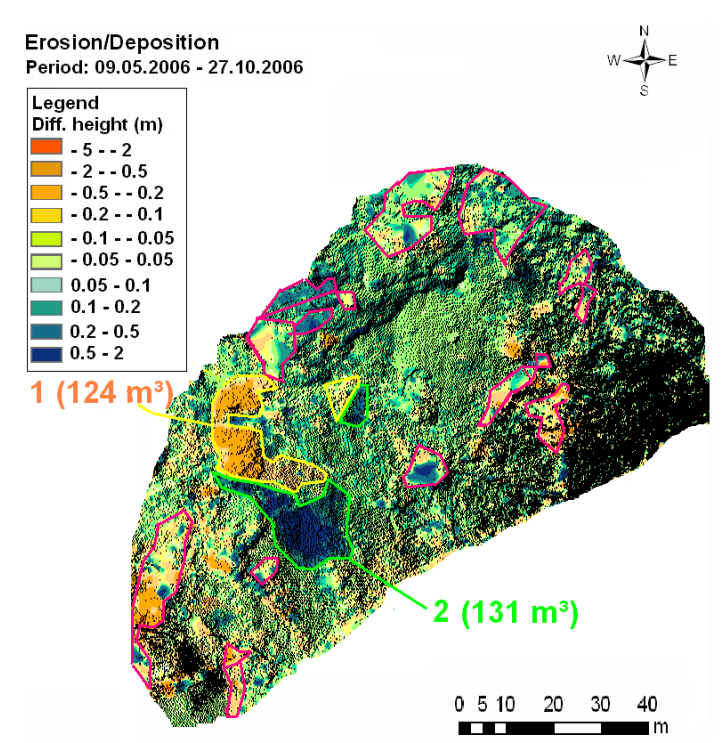

Fig. 4. Interpretation of slope movement patterns: all pink framed zones can be neglected due to low point density. Area 1 (yellow framed area indicates middle point density quality) moved downwards to area 2 (green framed area indicates high point density). Approximately $130 \mathrm{~m}^{3}$ of material was involved in the movement process.

creation of IDW-and a minimum surface) needs an operatordefined radius on the $\mathrm{x}, \mathrm{y}$ plane as a basis for calculation to filter points on the height-axis. For creation of the final DEM this means that the available points for the filter calculation and definition of the radius size influence the final result.
Finally, the sizes of displacement vectors were analysed. No significant difference in the deviation between TLS and tachymetry between areas with or without vegetation is visible. This is explained by the fact that only areas with high point cloud density were used to create displacement vectors, because the same points on the surface were located in consecutive scans. The existing error (mean: $41 \mathrm{~mm}$ and $56 \mathrm{~mm}$, max: $78 \mathrm{~mm}$ and $81 \mathrm{~mm}$ ) is explained by the difficulty in locating exactly the same point on the surface of two consecutive orthophotos.

For the whole area and monitoring period, the erosion and deposition of material was mapped in Fig. 3. To analyse the real mass balance of the slope, the point density must be taken into account. Figure 4 shows areas where the point density is low and the obtained DEM quality is uncertain (pink framed areas). This helps the operator make reliable conclusions about movement patterns. A volume of $124 \mathrm{~m}^{3}$ eroded at area 1 (yellow framed area with middle point density quality) and $131 \mathrm{~m}^{3}$ accumulated at area 2 (green framed area with high point density). All pink framed zones can be neglected due to low point density concerning slope movement patterns.

\section{Conclusions}

The capability of TLS to monitor slow moving landslides was assessed (movement rates $<100 \mathrm{~mm}$ per period). In a comparative study with tachymetry, accuracy limitations were defined for a case example. The analyses included the process of registering the scanner position, raw data and post processed data delivered by TLS, which is a crucial step for 
considering long term TLS monitoring of an object. In the case presented, an ICP algorithm was applied to improve the registration process. The registration error could be reduced significantly. Comparing raw data from TLS (measurements were executed over distances of $100 \mathrm{~m}$ ) to tachymetry the expected error due to decreased point accuracy of TLS measurements was approved (deviation $<17 \mathrm{~mm}$ ). The main focus of the presented investigation is the reliability of DEMs created from the TLS data concerning slope movement patterns. Filtering methods of point cloud data were investigated for slopes with and without vegetation cover. It can be concluded that if high accuracy is crucial for a monitoring project of slopes having vegetation cover, then manual filtering has advantages over automated filtering methods (mean deviation to tachymetry measurement: manually filtered: $51 \mathrm{~mm}$, automated filtered: $127 \mathrm{~mm}$ ). After analysis of the whole data set, including comparison of displacement vectors, it can be further concluded that using the presented methodology, including standard GIS tools for filtering applications, it is not possible to determine movement rates $<50 \mathrm{~mm}$ per investigated period. However, if the point density (the basis for DEM creation) is analysed, reliable conclusions can be made regarding slope movement patterns and erosion and deposition of material.

Acknowledgements. The work was funded by the EU-Research Project ClimChAlp (Climate Change, Impacts and Adaptation Strategies in the AlpineSpace), Work Package 6: Monitoring, Prevention and Management of Specific Effects of Climate Change on Nature and the Torrent and Avalanche Control Austria, section Vorarlberg. We thank Martina Mittelberger for some tachymetry measurements and Christina Delaney for assisting proof-reading. Moreover we thank Thierry Oppikofer and the anonymous reviewer whose comments substantially helped to improve the paper.

Edited by: M.-H. Derron

Reviewed by: T. Oppikofer and another anonymous referee

\section{References}

Abellán, A., Vilaplana, J. M., and Martínez, J.: Application of a long-range terrestrial laser scanner to a detailed rockfall study at Vall de Núria (Eastern Pyrenees, Spain), Eng. Geol., 88, 136$148,2006$.

Abellán, A., Jaboyedoff, M., Oppikofer, T., and Vilaplana, J. M.: Detection of millimetric deformation using a terrestrial laser scanner: experiment and application to a rockfall event, Nat. Hazards Earth Syst. Sci., 9, 365-372, 2009, http://www.nat-hazards-earth-syst-sci.net/9/365/2009/.

Axelsson, P.: DEM generation from Laser Scanner Data Using Adaptive TIN Models, Int. Arch. of Photogrammetry and Remote Sensing, 33, Part B4/1, 110-117, 2000.

Besl, P. J. and McKay, N. D.: A method for registration of 3-d shapes, IEEE Trans. Pat. Anal. and Mach. Intel., 14(2), 239-256, 1992.
Biasion, A., Bornaz, L., and Rinaudo, F.: Laser scanning on disaster management. In: Geo-information for disaster management, Springer Verlag Berlin Heidelberg 2005, 19-35, 2005.

Bitelli, G., Dubbini, M., and Zanutta, A.: Terrestrial laser scanning and digital photogrammetry techniques to monitor landslide bodies. Proceedings of the XXth ISPRS Congress, Istanbul, XXXV, part B5, 246-251, 2004.

Derron, M.-H., Jaboyedoff, M., and Blikra, L. H.: Preliminary assessment of rockslide and rockfall hazards using a DEM (Oppstadhornet, Norway), Nat. Hazards Earth Syst. Sci., 5, 285-292, 2005 , http://www.nat-hazards-earth-syst-sci.net/5/285/2005/.

Dewitte, O. and Demoulin, A.: Morphometry and kinematics of landslides inferred from precise DTMs in West Belgium, Nat. Hazards Earth Syst. Sci., 5, 259-265, 2005, http://www.nat-hazards-earth-syst-sci.net/5/259/2005/.

Hamrah, M., Shojaee, D., and Mosavi, A.: Evaluation of DTM Generation in Surfer 8.0. E - Conference Proceedings of Map India 2006, http://www.gisdevelopment.net/proceedings/mapindia/ 2006/student\%20oral/mi06stu_128.htm, 2006.

Hsiao, K. H., Yu, M. F., Liu, J. K., and Tseng, Y. H.: Change Detection of Landslide Terrains Using Ground -based Lidar Data, Proceedings of 2003 Annual Symposium of the Society of Chinese Association of Geographic Information, 2003.

Ingensand, H.: Methodological aspects in terrestrial laser-scanning technology, Proceedings of the 3rd IAG Symposium of Geodesy for Geotechnical and Structural Engineering and 12th FIG Symposium on Deformation Measurements, 22-24 May, Baden, Austria, On a CD, 2006.

Kilian, J., Haala, N., and Eenglich, M.: Capture and evaluation of airborne laser scanner data. International Archives of Photogrammetry and Remote Sensing, Vol. XXXI, Part B3. Vienna. 1996.

Lichti, D. and Jamtsho, S.: Angular resolution of terrestrial laser scanners, Photogrammetric Record, 21(114), 141-160, 2006.

Lindenberger, J.: Laser-Profilmessungen zur topographischen Geländeaufnahme, DGK Reihe C, Heft Nr. 400, 1993.

Mikos, M., Vidmar, A., and Brilly, M.: Using a laser measurement system for monitoring morphological changes on the Strug rock fall, Slovenia, Nat. Hazards Earth Syst. Sci., 5, 143-153, 2005, http://www.nat-hazards-earth-syst-sci.net/5/143/2005/.

Oppikofer, T., Jaboyedoff, M., and Keusen, H. R.: Collapse at the eastern Eiger flank in the Swiss Alps, Nature Geoscience, 1, 531535, 2008.

Pfeifer, N., Köstli, A., and Kraus, K.: Interpolation and filtering of laser scanner data - implementation and first results, in: International Archives of Photogrammetry and Remote Sensing, 32(3/1), Columbus, 153-159, 1998.

Pieraccini, M., Casagli, N., Luzi, G., Tarchi, D., Mecatti, D., Noferini, L., and Atzeni, C.: Landslide monitoring by ground based radar interferometry: a field test in Valdarno (Italy), Int. J. Remote Sens., 24(6), 1385-1391, 2003.

Prokop, A.: The application of terrestrial laser scanning for monitoring natural hazards, International Research Society INTERPRAEVENT (Hrsg.), In: Mikos, M., Hübl, J. (Eds.), Extended Abstracts, 11th Congress INTERPRAEVENT 2008, 2630 Mai 2008, Dornbirn, 332-334, 2008a.

Prokop, A.: Assessing the applicability of terrestrial laser scanning for spatial snow depth measurements, Cold Reg. Sci. Technol., 54, 155-163, 2008b. 
Prokop, A., Schirmer, M., Rub, M., Lehning, M., and Stocker, M.: A comparison of measurement methods: terrestrial laser scanning, tachymetry and snow probing for the determination of the spatial snow-depth distribution on slopes, Ann. Glaciol., 49, 210-216, 2008.

Prokop, A. and Panholzer, H.: Monitoring landslides using terrestrial laser scanning. Final report: EU-Research Project ClimChAlp (Climate Change, Impacts and Adaptation Strategies in the AlpineSpace), Work Package 6: Monitoring, Prevention and Management of Specific Effects of Climate Change on Nature, 31-34 and 108-112, 2007.

Scheidl, C., Rickenmann, D., and Chiari, M.: The use of airborne LiDAR data for the analysis of debris flow events in Switzerland, Nat. Hazards Earth Syst. Sci., 8, 1113-1127, 2008, http://www.nat-hazards-earth-syst-sci.net/8/1113/2008/.

Schulz, W. H.: Landslide susceptibility revealed by LIDAR imagery and historical records, Seattle, Washington, Engineering Geology, 89(1-2), 67-87, 2007.

Sithole, G. and Vosselmann, G.: Report: ISPRS Comparison of Filters. Department of Geodesy, Faculty of Civil Engineering and GeoSciences, Delft University of Technology, 2003.
Von Hansen, W. and Vögtle, T.: Extraktion der Geländeoberfläche aus flugzeuggetragenen Laserscanner-Aufnahmen, PFG 1999(4), 299-236, 1999.

Vosselmann, G. and Maas, H.-G.: Adjustment and Filtering of Raw Laser Altimetry Data. Proceedings of OEEPE Workshop on Airborne Laserscanning and Interferometric SAR for Detailed Digital Elevation Models, 1-3 March, 2001.

Vosselmann, G.: Slope-based filtering of laser altimetry data. Int. Arch. of Photogrammetry and Remote Sensing, 33(B3/2), 935942, 2000.

Voyat, I., Roncella, R., Forlani, G., and Ferrero, A. M.: Advanced techniques for geo structural surveys in modelling fractured rock masses: application to two Alpine sites. Proceeding: The 41st US Symposium on Rock Mechanics (USRMS): "50 Years of Rock Mechanics - Landmarks and Future Challenges", Colorado, 2006.

Wack, R. and Wimmer, A.: Digital terrain models from laser scanner data. A grid based approach. ISPRS Commission III, Symposium, 9-13 September, Graz, Austria, 2002. 